\title{
An Old Complication of a New Technique: Pneumorrhachis from Caudal Epidural Pulsed Radiofrequency
}

\section{TO THE EDITOR:}

Pulsed radiofrequency (PRF) has been used to manage various chronic pain conditions, such as cervical, dorsal, and lumbar radicular pain; post herpetic neuralgia; idiopathic trigeminal neuralgia; shoulder pain; meralgia paresthetica (1); pudendal neuralgia; coxal pain; phantom pain; facet syndrome; sacroiliac pain; arthrogenic pain; and coccygodynia. PRF is usually applied adjacent to the root ganglion, peripheral nerve, or intraarticularly $(2,3)$.

Caudal epidural PRF (CEPRF) is a new approach (4) that could be indicated for the simultaneous treatment of several roots in patients with failed back surgery syndrome plus arthrodesis or in those in whom anatomical distortion makes the transforaminal route impossible.

A 70-year-old woman presented with a one-year history of low back pain radiating posteriorly to the left thigh and leg; in the 3 weeks prior, the pattern had changed to include the anterior leg and parethesia. The pain appeared on walking several steps and subsided on sitting. The pain was unresponsive to analgesics, nonsteroidal anti-inflammatory drugs, and corticosteroids. Two epidural injections, at another center, resulted in

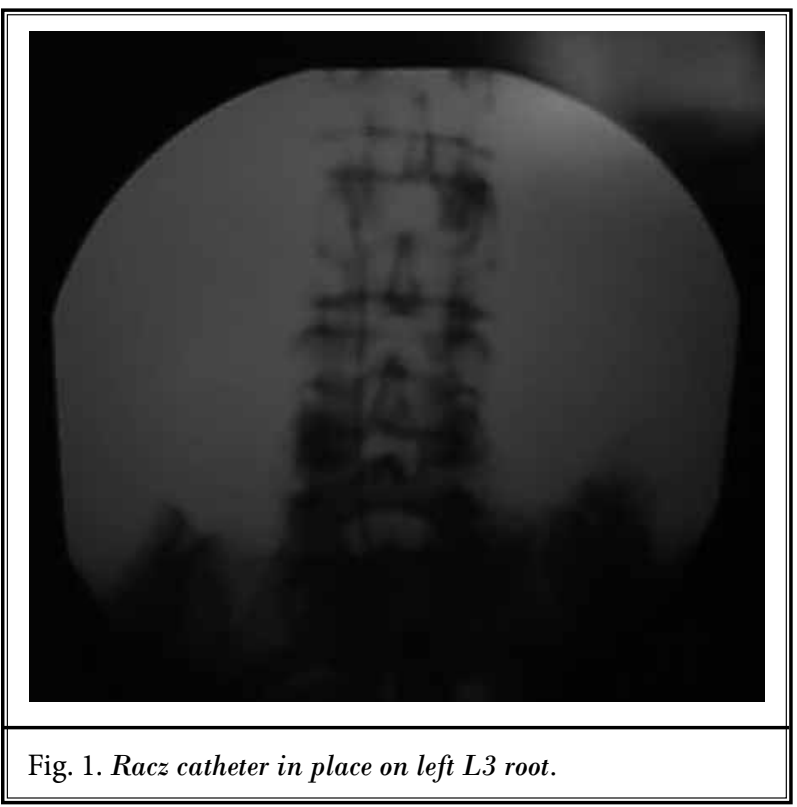

temporary relief. Physical examination revealed radiating pain and lumbar spine stiffness on flexion and on left lateral bending as well as tenderness on the L3 spinal process. Spinal reflexes were present without motor or sensory deficits. The anterior straight-leg-raising test was negative and the posterior straight-leg-raising was positive on the left side.

Plain-film x-rays showed grade I degenerative spondylolisthesis at the L3-L4 level, magnetic resonance imaging (MRI) also showed disc pseudobulging, facet hypertrophy, and lateral recess stenosis at the same level. After PRF applied to the dorsal root ganglion of the left $L 3$ root was unsuccessful the patient provided informed consent for CEPRF on the left L3 root. After the procedure, we injected a solution of $40 \mathrm{mg}$ triamcinolone in $2 \mathrm{~mL} 0.25 \%$ bupivacaine and $5 \mathrm{~mL}$ saline via the Racz catheter (Fig. 1). Two weeks later, pain had decreased by $75 \%$.

However, after a second L3-L4 CEPRF procedure performed with the same protocol, the patient experienced paraplegia, consisting of bilateral weakness and anesthesia of the lower limbs and pudendal area that lasted several hours. She also had transient minor headache.

Computed tomography (CT) showed pneumorrhachis at the L3-L4 level (Fig. 2).

Six weeks later, the patient was free of pain without air outside the dura mater spinalis.

Eight months later, a surgical procedure was done at another center for pain recurrence.

Pneumorrhachis, or free air on the inside or the outside of the dura mater spinalis, is uncommon; it was first described in 1977 (5) and the term was coined in 1987 (6). Other terms for this phenomenon include intraspinal pneumocele, spinal epidural and subarachnoid pneumatosis, spinal and epidural emphysema, aerorachia, or pneumosaccus (7). The technique of intentionally introducing air into the spinal canal for diagnostic purposes is called air myelography or pneumomyelography.

Various conditions can cause pneumorrhachis, including trauma, respiratory complications, and condi- 
tions that produce high intrathoracic pressure, malignancy and its therapy, and diagnostic or therapeutic procedures. As in our case, peridural or epidural administration of anaesthesia involving lumbar puncture can also cause pneumorrhachis (7-15). The air can dissect between the paraspinal soft tissues into the epidural or intradural space, becoming entrapped due to a oneway air valve mechanism or it can penetrate directly into the spinal canal by traumatic or medical manipulations, as in the present case. Furthermore, in the case reported, the transient neurological deficit and headache suggest leakage of cerebrospinal fluid and subdural local anesthetic penetration into the subdural space. Unfortunately we didn't inject a contrast agent. Our experience suggests it would be useful to inject contrast agents during all CEPRF procedures.

Pneumorrhachis is usually benign and the air reabsorbs spontaneously, as in our case.

Although neurological complications have been reported only in exceptional cases, they might be more common than reported (13). Kennedy et al (12) reported a case of lumbar root compression and bilateral L2-L3 sensory and motor deficit secondary to epidural air resulting from repeated air injection during administration of epidural analgesia via a continuous infusion pump; neurological symptoms resolved after decompression by percutaneous epidural air aspiration. Nay et al (15) reported a case of unilateral L2-L4 motor and sensory deficit due to nerve root displacement after injecting $40 \mathrm{~mL}$ of air to locate the extradural space by the "loss of resistance to air" technique for anesthesia. Gracia et al (10) reported a case of acute radicular pain attributed to air trapped in the epidural space after using the "loss of resistance saline" technique with epidural catheterization for epidural anaesthesia, suggesting that using saline instead of air is no guarantee against this complication. Finally, Krishnan and Mallick (13) reported a case of reversible sensory deficit and weakness in dermatomes L4-L5 attributed to epidural air after the "loss of resistance to air" technique (13). Other authors have suggested that epidural bubbles may be a cause of incomplete analgesia during epidur-

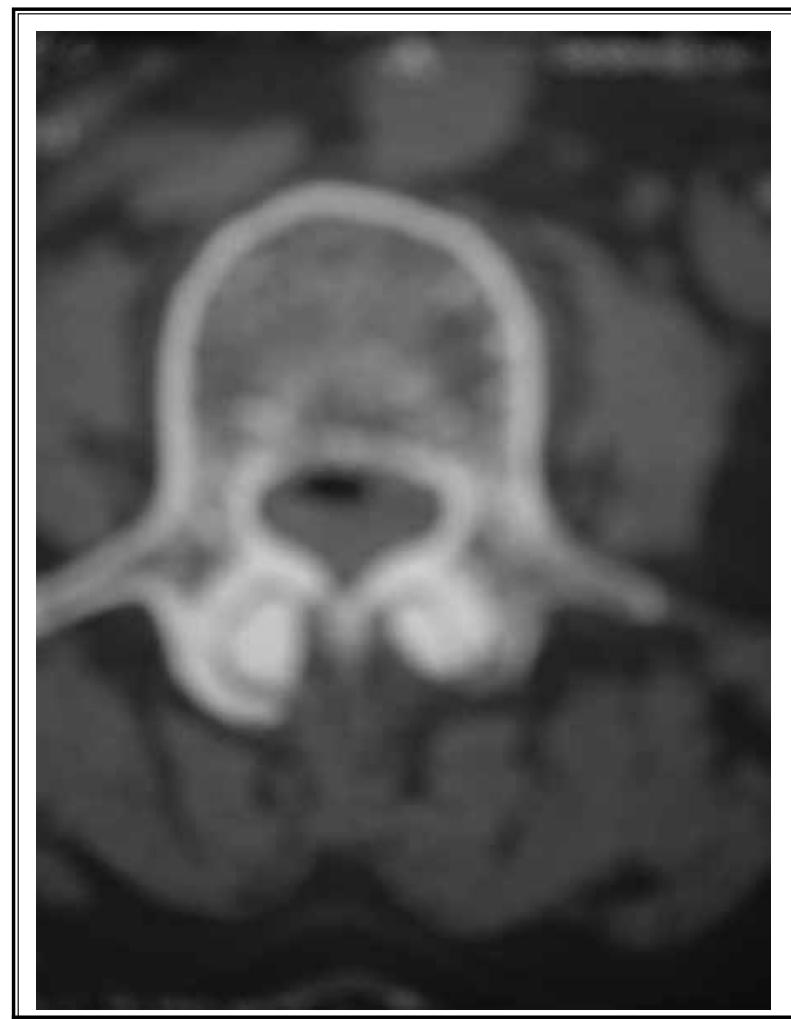

Fig. 2. Axial CT scan of the lumbar spine, bone window setting, showing extradural air collection within the ventral spinal canal.

al anesthesia $(8,9)$. If entrapped intraspinal air under pressure enters the cranio-spinal compartment it might cause tension pneomorrhachis and pneumocephalus requiring intervention.

CT and MRI are the most reliable techniques to detect pneumorrhachis (10).

In conclusion, we report a case of pneumorrhachis that developed after CEPRF and resolved spontaneously.

Joan Dalmau-Carolà, MD

Bisbe Lorenzana, 39,3-3

Girona, Catalonia, Spain

E-mail: jdalmauc@acmcb.es 


\section{References}

1. Dalmau-Carolà J. Treatment of meralgia paresthetica with pulsed radiofrequency of the lateral femoral cutaneous nerve. Pain Physician 2009; 12:1025-1026.

2. Atim A, Ergin A, Biliç S, Deniz S, Kurt E. Pulsed radiofrequency in the treatment of coccygodynia. Agri 2011; 23:1-6.

3. Van Boxem K, Van Eerd M, Brinkhuize T, Patijn J, Van Kleef M, Zundert JV. Radiofrequency and pulsed radiofrequency treatment of chronic pain syndromes: The available evidence. Pain Practice 2008; 8:385-393.

4. Insausti J, Uriarte E, García-Rueda A, Reig E, Abejón $D$, Del Pozo $C$ et al. Lumbosacral roots radiofrequency with Racz catheter. A new approach in selected patients with arthrodesis or anatomical deformities. Pain Practice 2009; 9:67.

5. Gordon J, Jartman DR. The traumatic pneumomyelogram. A previously undescribed entity. Neuroradiology 1977; 13:107-108.

6. Newbold RG, Wiener MD, Vogler JB 3rd, Martinez S. Traumatic pneumorrhachis. AJR Am J Roentgenol 1987; 148:615-616.

7. Oertel MF, Korinth MC, Reinges MHT, Krings T, Terbeck S, Gilsbach JM. Pathogenesis, diagnosis and management of pneumorrhachis. Eur Spine J 2006;
15:636-643.

8. Boezaart AP, Levendig BJ. Epidural air-filled bubbles and unblocked segments. Can J Anaesth 1989; 36:603-604.

9. Dalens B, Bazin JE, Haberer JP. Epidural bubbles as a cause of incomplete analgesia during epidural anesthesia. Honest Analg 1987; 66:679-683.

10. Gracia J, Gomar C, Riambau V, Cardenal C. Radicular acute pain after epidural anaesthesia with the technique of loss of resistance with normal saline solution. Anaesthesia 1998; 54:166-171.

11. Hirsch M, Katz Y, Sasson A. Spinal cord compression by unusual epidural air accumulation after continuous epidural analgesia. AJR Am J Roentgenol 1989; 153:887-889.

12. Kennedy T, Ullman DA, Harte FA, Lloyd R, Saberski LR, Greenhouse BB. Lumbar root compression secondary to epidural air. Anesth Analg 1988; 67:1184-1186.

13. Krishnam, Mallick A. Air in the epidural space leading to neurological deficit. Anaesthesia 2003; 58:280-300.

14. Miguel R, Morse S, Murtagh R. Epidural air associated with multiradiclar syndrome. Anesth Analg 1991; 73:92-94.

15. Nay PG, Milaszkiewicz R, Jothiliganm S. Extradural air as a cause of paraplegia following lumbar analgesia. Anaesthesia 1993; 48:402-404. 